\title{
Heat transfer analysis of liquid piston compressor for hydrogen applications
}

\author{
Kermani, Nasrin Arjomand; Rokni, Masoud
}

Published in:

International Journal of Hydrogen Energy

Link to article, DOI:

10.1016/j.ijhydene.2015.01.098

Publication date:

2015

Document Version

Peer reviewed version

Link back to DTU Orbit

Citation (APA):

Kermani, N. A., \& Rokni, M. (2015). Heat transfer analysis of liquid piston compressor for hydrogen applications. International Journal of Hydrogen Energy, 40, 11522-11529. https://doi.org/10.1016/j.ijhydene.2015.01.098

\section{General rights}

Copyright and moral rights for the publications made accessible in the public portal are retained by the authors and/or other copyright owners and it is a condition of accessing publications that users recognise and abide by the legal requirements associated with these rights.

- Users may download and print one copy of any publication from the public portal for the purpose of private study or research.

- You may not further distribute the material or use it for any profit-making activity or commercial gain

- You may freely distribute the URL identifying the publication in the public portal

If you believe that this document breaches copyright please contact us providing details, and we will remove access to the work immediately and investigate your claim. 


\title{
Original article: \\ Heat Analysis of Liquid piston Compressor for Hydrogen Applications
}

\author{
Nasrin Arjomand Kermani, and Masoud Rokni* \\ Thermal Energy Section, Department of Mechanical Engineering, Technical University of Denmark, \\ Nils Koppels Allé, Building 403, 2800 Lyngby, Denmark. \\ *Correspondence should be addressed to: Masoud Rokni \\ Tel:+45 452541 24, E-mail: $\underline{\text { mr@mek.dtu.dk }}$
}

\begin{abstract}
A hydrogen compression technology using liquid as the compression piston is investigated from heat transfer point of view. A thermodynamic model, simulating a single compression stroke, is developed to investigate the heat transfer phenomena inside the compression chamber. The model is developed based on the mass and energy balance of the hydrogen, liquid, and the wall of the compression chamber at each time step and positional node with various compression ratios, to calculate the temperature distribution of the system. The amount of heat extracted from hydrogen, directly at the interface and through the walls, is investigated and compared with the adiabatic case. The results show that depending on heat transfer correlation, the hydrogen temperature reduces slightly between $0.2 \%$ and $0.4 \%$ compared to the adiabatic case, at 500 bar, due to the large wall resistance and small contact area at the interface. Moreover, the results of the sensitivity analysis illustrates that increasing the total heat transfer coefficients at the interface and the wall, together with compression time, play key roles in reducing the hydrogen temperature. Increasing the total heat transfer coefficient at the interface (10000 times) or at the wall (200 times), leads to $22 \%$ or $33 \%$ reduction of hydrogen, compared to the adiabatic case, at 500 bar, during 3.5 seconds compression, respectively.
\end{abstract}

Keywords: Liquid piston, Hydrogen compression, Thermodynamic model, Energy balance, Heat analysis 


\section{Introduction}

On board high-pressure hydrogen storage is an interesting option for the car manufacturers to provide hydrogen-powered vehicles that could compete with gasoline vehicles [1]. This technology requires compressing and storing hydrogen above 700 bar at fueling stations [2] which significantly increases the hydrogen delivery cost. Compression of the hydrogen to such high pressure and followed by cooling down the hydrogen to $-40{ }^{\circ} \mathrm{C}$ before refueling [2] is an area with high potential for efficiency improvement and reduction of power consumption. Although reciprocating compressors are widely used for hydrogen compression, they are associated with several limitations such as; 1) engagement of numerous moving parts, which is expensive to manufacture, difficult to maintain, and have short life time, 2) Lack of internal-cooling possibility during the compression processes, due to movement of the solid piston, and consequent necessity of pre-cooling the hydrogen prior to refueling. Therefore, novel ideas are required to improve the system functionality and make it more feasible from energy and cost point of view. Liquid piston compressor is a unique approach that can be applied to explore such prospects. As indicated by its name, in this approach the solid piston used in conventional reciprocating compressors is replaced by a liquid piston.

The liquid piston concept was applied for the first time in an internal combustion engine known as Humphrey pump in 1906 [3]. However, to our knowledge, very few studies have investigated the heat transfer phenomena inside the compression chamber of the liquid piston compressors. A liquid piston compression was proposed as a concept to improve the behavior and the efficiency of the gas compression and expansion [4]. In this study, the compression chamber was divided to several small bores to improve the surface area to volume ratio in the working chamber [4]. Similar methodology as [4] has been used in [5] for developing numerical method, using finite difference method to investigate the theoretical efficiency of liquid piston and recognize optimal system characteristics. Moreover, a thermodynamic model for a two stage liquid piston compressor, applied in the compressed air energy storage systems has been developed before [6]. However, none of these studies considered the real properties of the operating gas and liquid, heat transfer through interface, and role of the compressor 's wall resistance [4][6]. Several other studies have investigated the trajectories of the compressor/ expander that lead to optimal tradeoff between efficiency and power in compressed air energy storage systems[7][8][9][10]. Although, heat transfer model plays an important role in finding the optimal 
trajectory, none of these studies used a detailed heat transfer model. The main objective of this study is to develop a detailed heat transfer model which covers most of the shortcomings which have not been covered in the previous studies mentioned above, in order to investigate the heat transfer phenomena inside the compression chamber of the liquid piston compressor and point out the critical parameters that could maximize the amount of heat which can be extracted from the compressed gas for further optimization purposes.

\section{Methodology}

A single compression stroke of a reciprocating liquid piston gas compressor is simulated to predict the heat transfer to the liquid, wall, and surrounding, and accordingly estimate the system pressure and temperature. Figure 1 represents the cross-sectional view of a compression chamber and outlines its components and schematic heat transfer mechanisms among those. As illustrated in Fig. 1, it is assumed that at each time step, the properties of liquid and gas are distributed uniformly, whereas the wall is discretized into $n$ positional nodes. A node system can be defined with "i" as the subscript identifying a node where the heat transfer occurs. At each time step the number of nodes in contact with liquid and gas is determined; consequently the wall temperature at each positional node is estimated. The model is build based on the properties of hydrogen, considering it as a real gas, and water, using EES Software [11]. All the properties of water and hydrogen are calculated at each time step based on the estimated temperature and pressure.

The application of this analysis is a single stage compressor to compress hydrogen for hydrogen refueling stations. The compressor is intake hydrogen at 100 bar and $303 \mathrm{~K}$ and compress it with a pressure ratio of 5:1 to 500 bar when running at a compression frequency of $2.5 \mathrm{~Hz}$. The compression chamber is a cylinder made of Stainless steel (AISI 316) with the wall thickness of $0.022 \mathrm{~m}$. Inside diameter, and the stroke length of the piston are 0.08 and $0.2 \mathrm{~m}$, respectively. The total displaced piston volume is $0.9 \mathrm{~L}$, considering the point that $10 \%$ of the volume is occupied by water from the beginning to avoid the penetration of Hydrogen into the hydraulic system. The speed of compressor is controlled by adjusting the rotating speed of hydraulic pump.

The following section develops the equations for the thermodynamic model analyzing the heat transfer inside the compression chamber. 


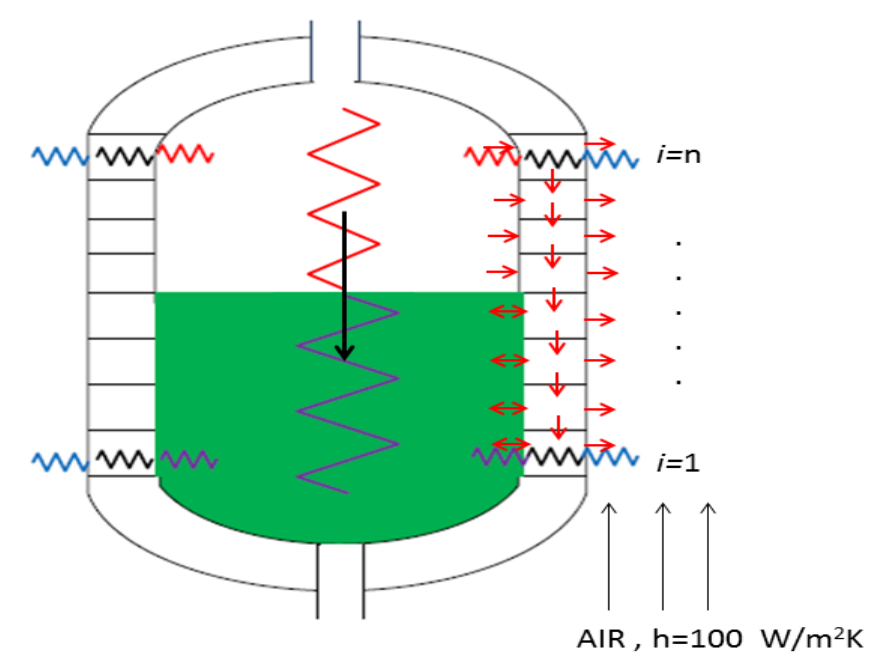

Figure 1 - the cross-sectional view of a compression chamber and schematic heat transfer mechanisms between the gas (white), the liquid (green) and the wall.

\subsection{Mass and energy balance}

Since the compression will start after the inlet valve is closed, the total amount of Hydrogen trapped in the compression chamber is constant during the compression procedure. Hence, the energy conservation of the gas is determined from the first law of thermodynamics for a closed system as following:

$$
\frac{d U_{\text {gas }}}{d t}=\frac{\delta Q}{\delta t}-\frac{\delta W}{\delta t} \rightarrow M_{g a s} \frac{d u_{\text {gas }}}{d t}=\dot{Q}_{g a s}+P \frac{d V}{d t}
$$

where $M_{g a s}$ is the total hydrogen mass inside the compression chamber, $d u_{\text {gas }} / d t$ is the change in internal energy of hydrogen, $\dot{Q}_{g a s}$ is the total rate of heat transfer between hydrogen and the wall, and hydrogen and the water, and $P d V / d t$ is the rate of work which is done by water on the gas side to compress hydrogen. The energy equation for the liquid has the following form

$$
\frac{d U_{l i q}}{d t}=\frac{\delta Q}{\delta t}-\frac{\delta W}{\delta t}-\frac{d H_{i n}}{d t} \rightarrow \frac{d}{d t}\left(M_{l i q} u_{l i q}\right)=\dot{Q}_{l i q}-P \frac{d V}{d t}+\frac{d}{d t} \sum\left(\dot{m}_{\text {liq }} h_{i n}\right)
$$


Since water is pumped into the compression chamber, the energy equation for open system is employed to the liquid, where $d H_{i n} / d t$ is the enthalpy flow of water entering the compression chamber. The enthalpy of water enters the compression chamber $\left(h_{i n}\right)$ is estimated based on isentropic efficiency of the pump and assuming the inlet conditions of $298 \mathrm{~K}$ and 1.013 bar for water. The isentropic efficiency of 0.7 is assumed for the pump. Moreover, $\dot{Q}_{\text {liq }}$ is the total rate of heat transfer between water and the wall, and water and hydrogen, and $M_{l i q}$ is water mass which can be calculated based on the constant mass flow rate as following

$$
\frac{d M_{l i q}}{d t}=\sum \dot{m}_{l i q} \rightarrow M_{l i q}-M_{l i q 0}=\int_{0}^{t} \dot{m}_{l i q} d t
$$

where $M_{l i q 0}$ is the initial water mass occupied compression chamber at time t $=0$ second.

$\dot{Q}_{g a s}$ and $\dot{Q}_{\text {liq }}$ are calculated based on

$$
\dot{Q}_{\text {gasliq }}=\sum_{i=m}^{i=n} \pm \dot{Q}_{w, i} \pm \dot{Q}_{\text {interface }}
$$

where $\dot{Q}_{w, i}$ is the rate of heat transfers between hydrogen or water and the wall estimated based on convection mechanism, and $\dot{Q}_{\text {interface }}$ is the rate of heat transfers between water and hydrogen estimated based on the conduction mechanism, at each time step. In order to estimate $\dot{Q}_{\text {liq }}$ in Eq. 4 , m is equal to 1 and $\mathrm{n}$ corresponds to the last node where water is in direct contact with the wall. However, for $\dot{Q}_{g a s}, \mathrm{~m}$ is equal to the node where hydrogen is in direct contact with water and $\mathrm{n}$ corresponds to the total number of discretization. 


\subsection{Heat transfer analysis}

The hydrogen temperature will increase during the compression procedure. Due to direct contact between the hydrogen and water, the heat will directly transfer from hydrogen to water based on newton's law of cooling

$$
\dot{Q}_{\text {interface }}=U A_{\text {interface }}\left(T_{\text {liq }}-T_{\text {gas }}\right)
$$

where $U A_{\text {interface }}$ is the total heat transfer coefficient and can be calculated based on conduction between water and hydrogen as

$$
U A_{\text {interface }}=\frac{1}{\sum R_{\text {total }}}
$$

where

$$
\sum R_{\text {total }}=\frac{L_{\text {liq }}}{K_{\text {liq }} A}+\frac{L_{\text {gas }}}{K_{\text {gas }} A}
$$

where $L_{\text {liqgas }}$ and $K_{\text {liqgas }}$ are the axial thickness and thermal conductivity of the water and hydrogen at each time step, and $A$ is the cross sectional area of the compression chamber.

Moreover, due to temperature difference between hydrogen and the compressor wall, heat begins to flow into the vessel's wall through convection; in which part of the heat will be absorbed by water and the rest will be transferred to the surrounding. Depending on the distance from bottom of the chamber, heat transfer coefficient of the gas, wall resistance, and the total amount of external cooling, water may absorb heat from the wall or transfer heat towards the wall. The amount of heat transfer from the liquid or the gas through the wall can be calculated as

$$
\dot{Q}_{w, i}=U A_{w, i}\left(T_{w, i}-T_{\text {gaslliq }}\right)
$$

where $T_{w, i}$ is the wall temperature at node $i$, and $U A_{w, i}$ is the total heat transfer coefficient which can be calculated based on total resistance of gas or liquid side and the wall

$$
U A_{w, i}=\frac{1}{\sum R_{\text {totallw, }}}
$$




$$
\sum R_{\text {total }, i}=\frac{1}{h_{i}\left(\pi D L_{i}\right)}+\frac{\ln \left(\frac{\frac{D}{2}+\frac{t_{w}}{2}}{\frac{D}{2}}\right)}{2 \pi L_{i} K_{w}}
$$

where $L_{i}=L / n$ and $L$ is equal to the total length of the piston, $t_{w}$ is the wall thickness, $n$ is the total number of nodes, $D$ is the piston diameter, $K_{w}$ and $h_{i}$ are the thermal conductivity of the wall and convective gas or liquid heat transfer coefficient, respectively.

The following energy balance in the wall is used to estimate the wall temperature, and the amount of heat which will transfer from the gas side towards water or to the surrounding at each positional node and time step.

$$
\begin{aligned}
& -\dot{Q}_{w, i+1}+\dot{Q}_{a x i a l, i+1}-\dot{Q}_{a x i a l, i}+\dot{Q}_{s u r, i+1}=0 \\
& i=2, \ldots, n-1
\end{aligned}
$$

where $\dot{Q}_{a x i a l, i}$ and $\dot{Q}_{s u r, i}$ stands for the axial conduction heat rate, and radial convection heat rate transfers inside the wall and towards the surrounding respectively, and it can be calculated as

$$
\begin{aligned}
& \dot{Q}_{a x a l, i}=K_{w} A_{w}\left(T_{w, i+1}-T_{w, i}\right) / L_{i} \\
& \dot{Q}_{s u r, i}=U A_{a i r}\left(T_{a m b}-T_{w, i}\right)
\end{aligned}
$$

In Eq. 12 and $13 A_{w}$ is the cross sectional area of the wall, $T_{a m b}$ and $U A_{\text {air }}$ are the ambient temperature and the total heat transfer coefficient between outlet flow and the wall. $U A_{\text {air }}$ can be calculated from

$$
\begin{aligned}
U A_{\text {air }}= & \frac{1}{\sum R_{t, i}} \\
\sum R_{t, i} & =\frac{1}{h_{\text {sur }} \pi\left(D+2 t_{w}\right) L_{i}}+\frac{\left(\frac{\frac{D}{2}+t_{w}}{\frac{D}{2}+\frac{t_{w}}{2}}\right)}{2 \pi L_{i} K_{w}}
\end{aligned}
$$


where $h_{\text {sur }}$ is the convective heat transfer coefficient to the surrounding. In the present study it is assumed that the wall will be cooled down by an external air flow with constant convective heat transfer coefficient equal to $100 \mathrm{~W} / \mathrm{m}^{2} \mathrm{~K}$.

The first step in estimation of the heat transfer coefficient of both water and hydrogen is to determine the flow regime, defined by the Reynolds-number(Re). Since a constant volume flow rate is assumed for the pump, the velocity of the liquid column is calculated based on the constant rate of piston travel as

$$
\operatorname{Re}=\frac{\rho_{\text {liq\gas }} V D}{\mu_{\text {liq gas }}} \quad \text { where } \quad V=\frac{\dot{v}}{A}
$$

Where $\rho_{\text {liq\gas }}$ and $\mu_{\text {liq\gas }}$ are density and viscosity of water or hydrogen respectively.

It is assumed that hydrogen has the same velocity as water all over the piston. This can be a good estimation for predicting the bulk motion of the gas. However, in reality this motion will decay throughout the end of the stroke. A fair amount of work have been done on estimation of the convective coefficient of the working gas such as [12][13][14][15][16][17][18][19]. Table 1 lists the widely used empirical heat transfer correlations available in the literature. All equations follow the general from of

$$
N u=A \operatorname{Re}^{a} \operatorname{pr}^{b} \frac{\mu^{c}}{\mu_{0}} \quad \text { where } \quad h=\frac{N u k}{D}
$$

where $N u, p r, k$ and $\mu$ are respectively Nusselt-number, Prandtl-number, thermal conductivity, and viscosity of the fluid. $\mu_{0}$ and $D$ are the viscosity of the fluid at inlet condition and the piston diameter, respectively. 
Table 1 - Seven widely used empirical heat transfer correlations

\begin{tabular}{cccccc}
\hline Name & Date & A & a & B & c \\
\hline Dittus \& Boelter & 1930 & 0.03 & 0.8 & 0.3 & 0.0 \\
[12][13] & & & & & \\
Sieder \& Tate [14] & 1936 & 0.03 & 0.8 & 0.3 & 0.1 \\
Annand [15][20] & 1963 & 0.70 & 0.7 & 0.7 & 0.0 \\
Adair et al. [16] & 1972 & 0.05 & 0.8 & 0.6 & 0.0 \\
Hamilton [17][20] & 1974 & 0.02 & 0.8 & 0.6 & 0.0 \\
Liu \& Zhou [18] & 1984 & 0.75 & 0.8 & 0.6 & 0.0 \\
Hsieh et al. [19] & 1996 & 0.16 & 1.1 & 0.0 & 0.1 \\
\hline
\end{tabular}

The first correlation in Table 1 is the Dittus \& Boelter correlation which estimates the fully developed turbulent heat transfer coefficient in circular tubes, with smooth surfaces and moderate temperature difference between the wall and fluid mean temperature. For flows characterized by large property variations, Sieder \& Tate recommended an extended Dittus \& Boelter correlation which also takes into account the wall effect when wall temperature differs significantly from the fluid mean temperature. Similarly, Hamilton proposed an alternative correlation to the Dittus \& Boelter correlation. However, in general, using Dittus \& Boelter correlation is only valid for fully developed flow where $L / D>60$ [21]. Since, this condition is not satisfied in most of the conventional compressor chambers, especially as the stroke moves towards the top dead center of the position, researchers like Annand, Adair et al., Liu \& Zhou, and Hsieh et al. proposed other correlations through experimental data.

Annand proposed a correlation for internal combustion engines, whereas neglecting the combustion terms and replacing Re-number by Peclet-number $(\operatorname{Re} \times \operatorname{Pr})$, the correlation can be used for the compressors with rather good accuracy [20], as shown in Table 1. Adair et al., Liu \& Zhou, and Hsieh et al. found other constants for Eq. 17 from the experimental results obtained originally for reciprocating compressors.

In order to find the best fit for the experimental data, Adair et al. and Liu \& Zhou used an alternative equation for calculating Reynolds-number which is based on time varying equivalent diameter and swirl velocity rather than the averaged piston speed, as 


$$
\operatorname{Re}^{*}=\frac{\rho_{g a s} v_{s} D_{e}}{\mu_{g a s}}
$$

and

$$
D_{e}=\frac{6 \text { volume }}{\text { Area }}=\frac{6 \pi \frac{D}{2} s(t)}{\pi D s(t)+2 \pi \frac{D^{2}}{2}}
$$

where $v_{s}$ is the swirl velocity, and $s(t)$ is the piston stroke. Since in the present work, water enters into the compression chamber with a constant volume flow rate, the swirl velocity, is estimated to be twice as the frequency of compression $\left(w_{g}\right)[6]$, as

$$
v_{s}=\frac{D_{e}}{2} w_{g}
$$

It should be mentioned that for calculating the convective coefficient of the liquid, Dittus \& Boelter equation which is shown in Table 1 is used. Furthermore, in case of longer compression period where the gas or liquid regime changed from turbulent to laminar condition Eq. 17 with $A=0.664, a=0.5$, $\mathrm{b}=0.3$ coefficients is used [22].

After defining all the parameters, Eq. 1, 2, and 3 can be solved simultaneously by using forward differencing numerical integration and updating the properties of the system at every time step based on the predicted temperature and pressure.

\section{Results and Discussion}

The results obtained for the heat analysis of reciprocating liquid piston compressor is presented in this section. Figure 2 shows the instantaneous Nusselt-number (Nu-number) derived from different correlations as a function of Reynolds-number (Re-number). The results show a significant difference between different correlations. It can be observed that the estimated $\mathrm{Nu}$-number based on three correlations suggested by Hamilton, Dittus \& Boelter, and Sieder \& Tate is very small. However, the $\mathrm{Nu}$-number estimated by Adair et al., Annand, and Liu \& Zhou correlations are approximately 2, 11, and 30 times larger than the one derived by Hamilton correlation. Moreover, the correlation suggested by Hsieh et al. estimated the largest Nu-number which is about 120 to 190 times larger than Hamilton. Figure 2 also illustrates that the Re-number which is calculated based on swirl velocity in Adair et al. 
and Liu \& Zhou correlations, vary within smaller range compared to the other correlations, and $\mathrm{Nu}-$ number starts to decrease from Re-number larger than $2.1 \times 10^{4}$. Such trend can be explained by decreasing the swirl movement of the gas as the piston moves towards the top dead center.
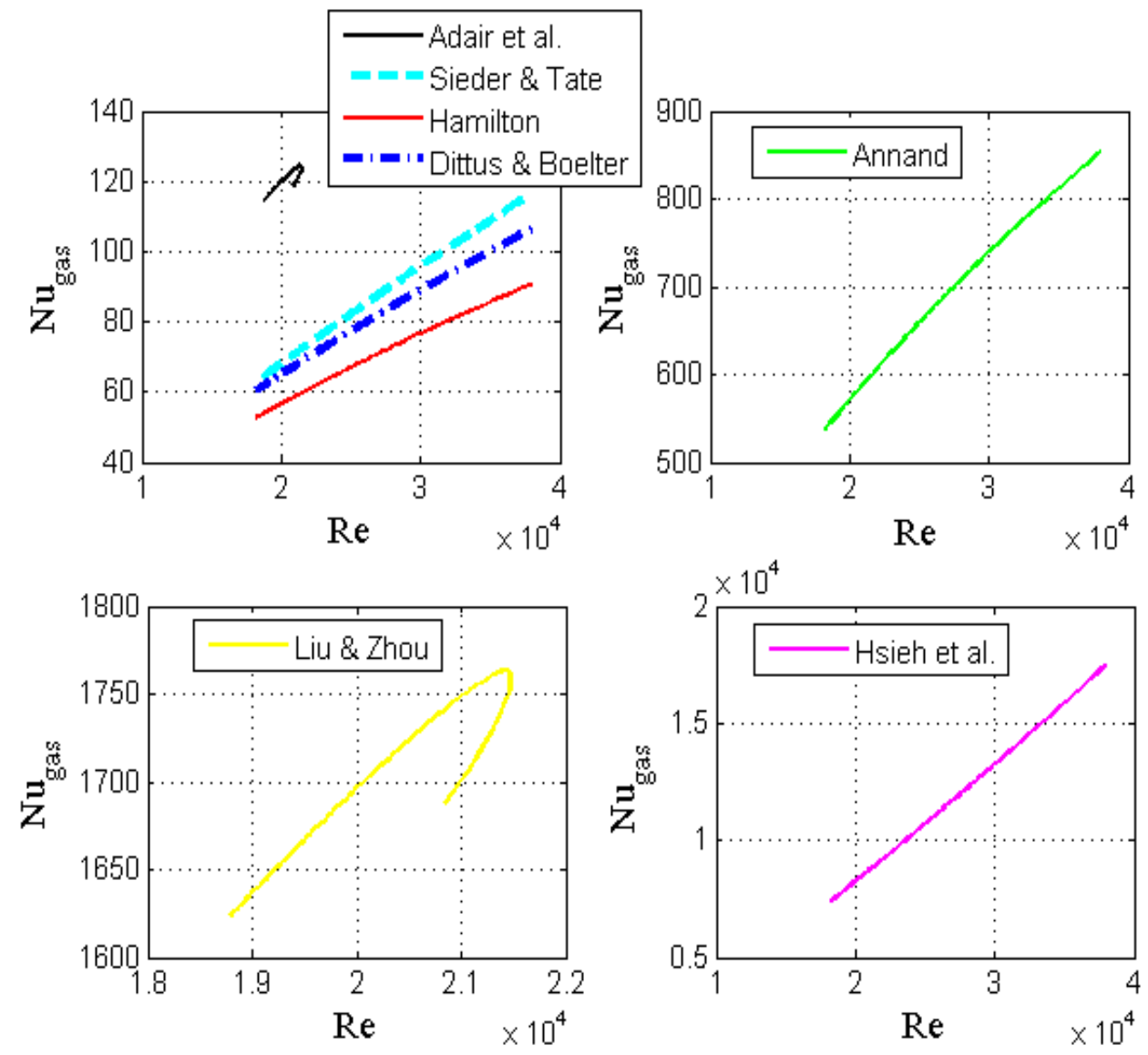

Figure 2 -Nusselt-number as a function of Reynolds-number, calculated based on seven different correlations

As the hydrogen is compressed from 100 to 500 bar, the hydrogen temperature will rise from $300 \mathrm{~K}$ to about $477 \mathrm{~K}$ in adiabatic case. When the hydrogen temperature exceeds the temperature of the cylinder wall, all the previously described correlations will predict heat transfer into the wall. Figure 3 shows the hydrogen temperature during the compression procedure, considering heat transfer at the interface and through the walls based on seven heat transfer correlations mentioned above, and compare them with the adiabatic case, for one set of operating conditions. The results show slight deviation of hydrogen temperature based on Hamilton, Dittues \& Boelter, and Sieder \& Tate compared 
to adiabatic case. Since these correlations estimate very small convective gas heat transfer coefficient, the amount of heat transfer towards the wall is very small. However, larger deviations of hydrogen temperature from adiabatic case are obtained based on other correlations.

Fagotti et al. has previously compared experimental results obtained for conventional reciprocating compressors with the results of heat transfer models where Annand, Adair et al., Hamilton, and Liu \& Zhou correlations used, and concluded that Annand correlation showed the best fit [20]. It was also pointed out that correlation suggested by Hamilton, results in almost no heat transfer [20], similar trend observed in the present study.

As expected, the largest deviation from adiabatic case is obtained from Hsieh et al. correlation, in which the estimated heat transfer coefficient of the gas is about 120 to 190 times larger than Hamilton correlation. However, even in this best case $\left(\mathrm{T}_{\text {hy, Hsieh et al. }}=475.4 \mathrm{~K}\right)$, only $0.4 \%$ reduction in hydrogen temperature is observed compared to the adiabatic case $\left(T_{\text {hy, Adiabatic }}=477.1 \mathrm{~K}\right)$ at 500 bar. Therefore, it can be concluded that the sensitivity of the model to different correlations is quite low. The main reason of that can be the large resistance of the wall which practically will avoid transferring of a considerable amount of heat inside the wall (more conductive walls can play an important role in decreasing the gas temperature). Furthermore, large resistance of the wall will also avoid the linear increasing of the total heat transfer coefficient with convective heat transfer coefficient of the gas, consequently transferring of more heat towards the wall (see second term of Eq. 10).

Unlike the developed model in the current study, In previous studies which have used the first law of thermodynamic and heat transfer correlations for prediction of gas temperature inside the compressor, wall temperature equal to ambient temperature is assumed [4][6]. Such models did not take into account the wall resistance, which is essential for estimation of the gas temperature inside the compressor.

Additionally, it can be observed in Fig. 3 that the interface does not play an important role in cooling the hydrogen temperature. It should also be mentioned that the current study only considers the conduction mechanism between liquid and gas, but in real conditions, heat transfer behavior may become more complicated than the conduction mechanism which may affect the results. 


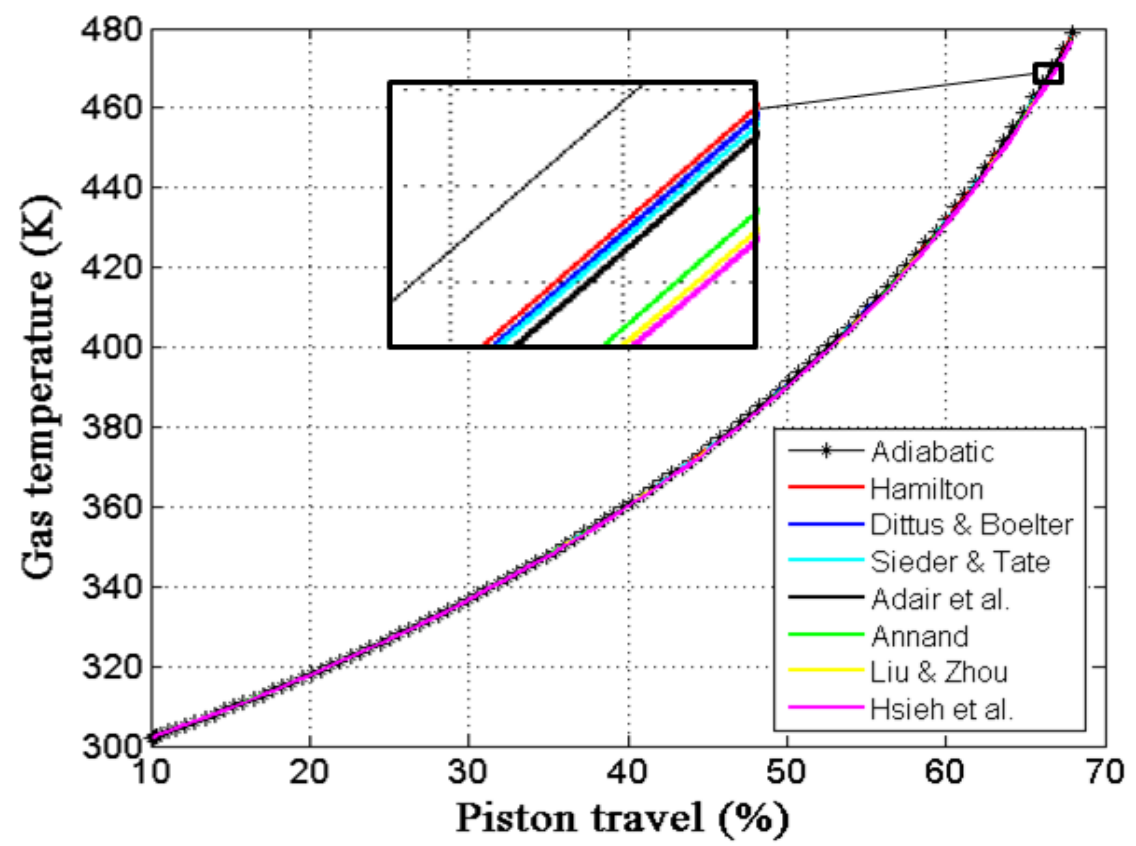

Figure 3 - Hydrogen temperature as a function of piston travel, calculated for seven different heat transfer correlations, as well as adiabatic case

Figure 4 shows the temperature distribution along the wall of compressor at the end of compression processes. As expected, the wall temperature at the top side of the compression chamber is closer to the temperature of the compressed hydrogen from the correlations that estimate larger heat transfer coefficients for the gas. Nevertheless, for correlations like Adair et al., Sieder \& Tate, Dittus \& Boelter, and Hamilton the temperature obtained at $19 \mathrm{~cm}$ from the bottom of the vessel deviates about $14 \%$, $16 \%, 16 \%$, and $16 \%$ from the hydrogen temperature $\left(\mathrm{T}_{\text {hy, Adiar et al. }}=476 \mathrm{~K}, \mathrm{~T}_{\text {hy, Sieder } \& \text { Tate }}=476.2 \mathrm{~K}, \mathrm{~T}_{\mathrm{hy}}\right.$, Dittus \& Boelter $=476.2 \mathrm{~K}$, and $\mathrm{T}_{\text {hy, Hamilton }}=476.23 \mathrm{~K}$ at $500 \mathrm{bar}$ ), respectively. Wall temperature distribution shows that for the nodes which are in direct contact with hydrogen the temperature is above $370 \mathrm{~K}$, whereas it decreases considerably towards the bottom side of the compression chamber. The bottom side of the compression chamber has almost the same temperature as water during compression, all the time. 

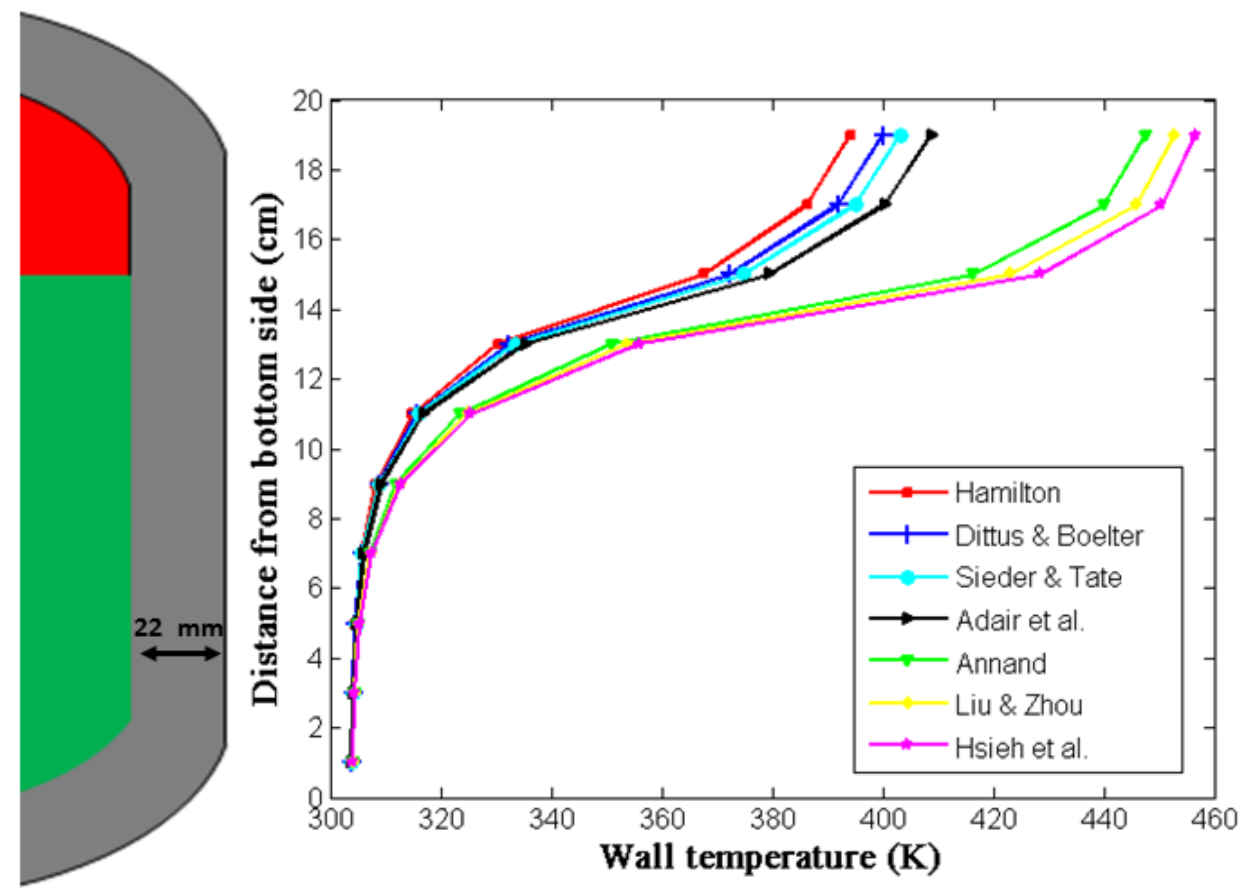

Figure 4 - Temperature distribution in cylinder wall, the colors inside the chamber represent the space inside compression chamber occupied by liquid (green) and the gas (red) at the end of compression processes

Equations 5, 8, and 14 show that increasing the total heat transfer coefficient, both at the interface and the wall, will increase the amount of heat flux and consequently reduce the hydrogen temperature. Table 2 shows the role of three parameters of total heat transfer coefficient at the interface, at the wall, and compression time, in reduction of hydrogen temperature from the adiabatic case.

Table 2 - Role of increasing (a) total heat transfer coefficient at the interface by factor of $F(b)$ at the wall by factor of $F$, and time on reduction of hydrogen temperature

\begin{tabular}{|c|c|c|c|c|c|}
\hline \multicolumn{3}{|c|}{$F \times U A_{-}$int (a) } & \multicolumn{3}{|c|}{$F \times U A_{a i r}, w(b)$} \\
\hline \multicolumn{3}{|c|}{$T_{\text {hydrogen }}(K)$ at 500 bar } & & \multicolumn{2}{|c|}{$T_{\text {hydrogen }}(K)$ at 500 bar } \\
\hline $\mathbf{F}$ & $t_{\text {comp }}=0.4 \mathrm{~s}$ & $t_{\text {comp }}=3.5 \mathrm{~s}$ & $\mathbf{F}$ & $t_{\text {comp }}=0.4 \mathrm{~s}$ & $t_{\text {comp }}=3.5 \mathrm{~s}$ \\
\hline 1000 & 472.9 & 452.2 & 50 & 434.1 & 362.3 \\
\hline 4000 & 465.1 & 413.1 & 100 & 408.2 & 340.2 \\
\hline 8000 & 455.3 & 381.7 & 150 & 391.2 & 330.6 \\
\hline 10000 & 450.8 & 371.4 & 200 & 379.3 & 319.0 \\
\hline
\end{tabular}


It can be seen that increasing the total heat transfer coefficient by factor of $\mathrm{F}$ and compression time, the deviation of hydrogen temperature compared to the adiabatic case will increase ( $\mathrm{T}_{\text {adiabatic }}$ at 500 bar $=477.1 \mathrm{~K})$.

Figure 5 shows the changes of pressure and temperature during 0.4 seconds and 3.5 seconds of compression, considering that the total heat transfer coefficient is 10000 times larger than what is estimated by Eq. 6 and using Annand correlation for calculating the convective coefficient of the gas.

Figure 5a shows lower pressure compared to adiabatic case for the above mentioned scenarios. The main reason of such behavior can be explained by significant reduction of temperature due to considerable increase of heat flux at the interface. As observed in Fig. 5b, the temperature reduction of $5-6 \%$ and $22 \%$ during the 0.4 and $3.5 \mathrm{~s}$ compression compared to adiabatic case, at 500 bar corresponding to $69 \%$ of piston travelling. Increasing the compression time leads to transfer of more heat from the gas side to liquid and consequently larger reduction of gas temperature.

Increasing the total heat transfer coefficient up to 10000 times larger than what is estimated, requires increasing the heat transfer area by the same amount. This is practically not passible by increasing the diameter versus the length of the cylinder. Spraying liquid into compression chamber can increase the contact area between liquid and gas considerably, but still requires a detailed modeling to estimate the total amount of heat transfer that can be removed when such technology is used.

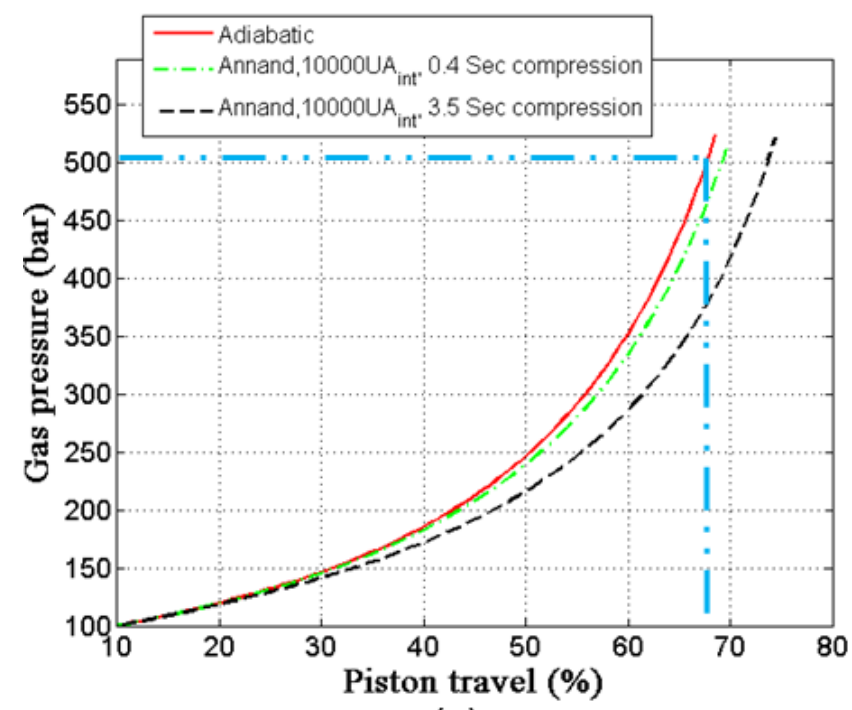

(a)

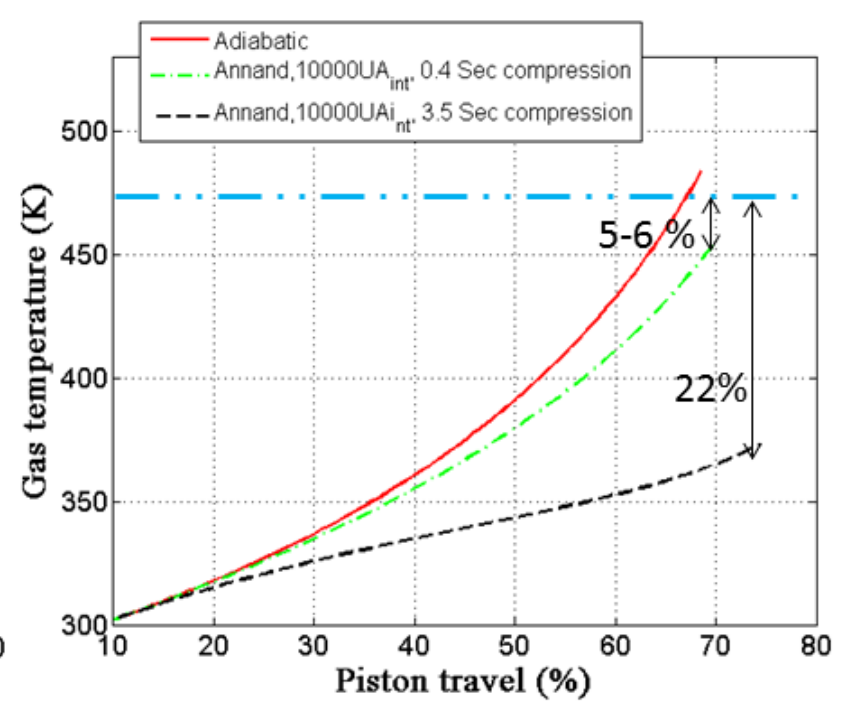

(b)

Figure 5 - Studying the role of total heat transfer coefficient at the interface, and compression time on reduction of (a) Hydrogen pressure and (b) Hydrogen temperature compared to adiabatic case 
Furthermore, increasing the total heat transfer coefficient between gas to wall, liquid to wall, and wall to air can also play an important role in decreasing the hydrogen temperature. As shown in Fig. 6, Hydrogen pressure during the compression decreases compared to adiabatic case, mainly due to the significant reduction of temperature. It can be seen in Fig. 6 that if the total heat transfer coefficient in both Eq. 8 and 14 increases up to 200 times more than what is estimated by the model developed here, the hydrogen temperature will decrease up to $20 \%$ and $33 \%$ according to Annand correlation for 0.4 and 3.5 seconds compression compared to adiabatic case, at 500 bar corresponding to $69 \%$ of piston travelling. Increasing the total heat transfer coefficient up to 200 times larger than what is estimated requires a considerable increase in the geometry from inside and outside of the compressor which practically is very difficult to reach.

Although increasing compression time also plays role in decreasing the temperature, there is a limitation regarding this parameter. The main reason of that is the considerable reduction of the hydrogen and water speed by increasing compression time which will lead to changes of the flow regime from turbulent to laminar condition. The heat transfer coefficients of the hydrogen and liquid will decrease in laminar regime, hence decreasing the total heat transfer coefficient.

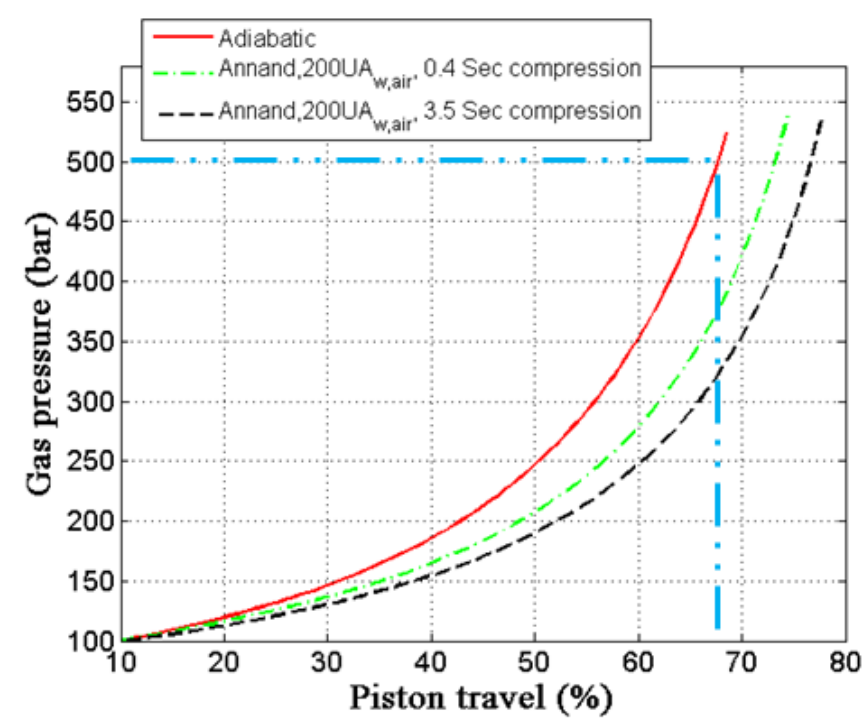

(a)

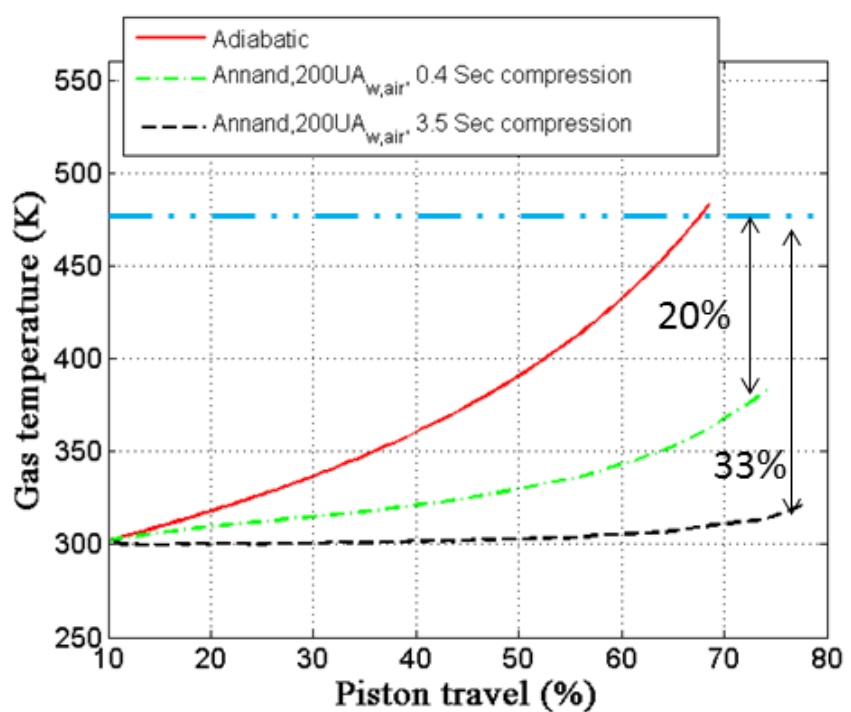

(b)

Figure 6 - Studying the role of total heat transfer coefficient at the wall, and compression time on reduction of (a) Hydrogen pressure and (b) Hydrogen temperature compared to adiabatic case 


\section{Conclusion}

This work presents a study on heat transfer analysis of liquid piston compressor. A model is developed based on the first law of thermodynamics in a reciprocating liquid piston compressor to predict the system's temperature and pressure at different time steps. The amount of heat transferred from the hydrogen towards the wall is estimated according to different heat transfer correlations. The results show small changes in hydrogen temperature, between $0.2 \%$ and $0.4 \%$, compared to adiabatic case, due to large wall resistance and small contact area between gas and liquid at the interface. Furthermore, sensitivity analysis of the model based on the total heat transfer coefficients at the interface and the wall, and the compression time proves the key role of these parameters in reduction of hydrogen temperature during the compression procedure. Increasing the total heat transfer coefficient at the interface (10000 times) or at the wall (200 times), leads to $6 \%$ or $20 \%$ reduction of hydrogen, compared to the adiabatic case, at 500 bar, during 3.5 seconds compression, respectively. Increasing the compression time to 3.5 seconds will lead to further reduction of hydrogen temperature to $22 \%$ or $33 \%$ respectively. Increasing total heat transfer coefficients requires increasing total heat transfer area by the same factor. Spraying liquid into the compression chamber can be considered as one of the practical techniques for increasing the total heat transfer area at the interface and further optimization purposes.

\section{Acknowledgements}

The authors would like to thank the Danish Council for Strategic Research with grant number DNF93 through Hyfill-fast project.

\section{References}

[1] S. Satyapal, J. Petrovic, C. Read, G. Thomas, and G. Ordaz, “The U.S. Department of Energy’s National Hydrogen Storage Project: Progress towards meeting hydrogen-powered vehicle requirements," Catal. Today, vol. 120, no. 3-4, pp. 246-256, Feb. 2007. 
[2] "J2601: Fueling Protocols for Light Duty Gaseous Hydrogen Surface Vehicles - SAE International,” 2010. [Online]. Available: http://standards.sae.org/j2601_201003/. [Accessed: 19-Dec-2014].

[3] H. A. Humphrey, "An internal-combustion pump, and other applications of a new principle," Arch. Proc. Inst. Mech. Eng. 1847-1982 (vols 1-196), vol. 77, no. 1909, pp. 1075-1200, Jun. 1909.

[4] J. D. Van de Ven and P. Y. Li, "Liquid piston gas compression," Appl. Energy, vol. 86, no. 10, pp. 2183-2191, Oct. 2009.

[5] C. Piya, "Numerical modeling of liquid piston gas compression," ASME Int. Mech. Eng. Congr. Expo. Proc., vol. 9, no. PART A, pp. 507 - 517, 2010.

[6] A. Dolatabadi, D. Fabris, and D. Samara-Rubio, "Isothermal Efficiency of Liquid Piston Compressors Employed in Compressed Air Energy Storage Systems," in Volume 1B, Symposia: Fluid Machinery; Fluid Power; Fluid-Structure Interaction and Flow-Induced Noise in Industrial Applications; Flow Applications in Aerospace; Flow Manipulation and Active Control: Theory, Experiments and Implementation; Fundamental Iss, 2013, vol. 1, p. V01BT12A003.

[7] C. J. Sancken, "Optimal Efficiency-Power Relationship For an Air Motor-Compressor in an Energy Storage and Regenration System," Proc. ASME Dyn. Syst. Control Conf. 2009, PTS a B, pp. $1315-1322,2010$.

[8] A. T. Rice, "Optimal Efficiency-Power Tradoff For an Air Motor/Compressor With Volume Varying Heat Transfer Capability," Proc. ASME Dyn. Syst. Control Conf. BATH/ASME Symp. FLUID POWER MOTION Control (DSCC 2011), VOL 1, pp. 145 - 152, 2012.

[9] M. Saadat, "Optimal Trajectories for a Liquid Piston Compressor/Expander in a Compressed Air Energy Storage System with Consideration of Heat Transfer and Friction," $2012 \mathrm{Am}$. Control Conf., pp. $1800-1805,2012$.

[10] F. A. Shirazi, "Iterative optimal and adaptive control of a near isothermal liquid piston air compressor in a compressed air energy storage system," Proc. Am. Control Conf., pp. 2934 2939, 2013.

[11] "EES: Engineering Equation Solver | F-Chart Software : Engineering Software." [Online]. Available: http://www.fchart.com/ees/. [Accessed: 13-Nov-2014].

[12] W. Dittus, "Heat transfer in automobile radiators of the tubular type," Univ. Calif. -- Publ. Eng., vol. 2, no. 13, pp. $443-461,1930$. 
[13] F. W. Dittus, "Heat Transfer In Automobile Radiators OF The Tubular Type.," Int. Commun. Heat Mass Transf., vol. 12, no. 1, pp. 3 - 22, 1985.

[14] E. Sieder, "Heat transfer and pressure drop of liquids in tubes," Ind. Eng. Chem., vol. 28, pp. $1429-1435,1936$.

[15] W. Annand, "Heat transfer in the cylinders of reciprocating internal combustion engines," Proc. Inst. Mech. ..., vol. 177, no. 1, pp. 973-996, 1963.

[16] R. Adair, E. Qvale, and J. Pearson, "Instantaneous heat transfer to the cylinder wall in reciprocating compressors," in I nternational Compressor Engineering Conferance, 1972, pp. $521-526$.

[17] J. Hamilton, "Extensions of mathematical modeling of positive displacement type compressors," in Short Course Text in Ray Herrick Laboratories, School of Mechanical Engineering, Purdue University, 1974, pp. 9-25.

[18] R. Liu and Z. Zhou, "Heat transfer between gas and cylinder wall of refrigerating reciprocating compressor," in International Compressor Engineering Conferance, 1984, pp. 110-115.

[19] W. H. Hsieh and T. T. Wu, "Experimental investigation of heat transfer in a high-pressure reciprocating gas compressor,” Exp. Therm. Fluid Sci., vol. 13, no. 1, pp. 44-54, Jul. 1996.

[20] F. Fagotti, M. Todescat, R. Ferreira, and A. Prata, "Heat transfer modeling in a reciprocating compressor," in International Compressor Engineering Conferance, 1994, p. paper 1043.

[21] W. M. Rohsenow, Handbook of Heat Transfer, 3rd ed. McGraw-Hill, 1998.

[22] Y. A. Cengel, Heat transfer : a practical approach. McGraw-Hill, 1998. 